\title{
Effect of Medicaid Policy Changes on Medication Adherence: Differences by Baseline Adherence
}

\author{
Krutika Amin, MSPH; Joel F. Farley, PhD; Matthew L. Maciejewski, PhD; and Marisa E. Domino, PhD
}

\begin{abstract}
BACKGROUND: In 2001, the North Carolina (NC) Medicaid program reduced the number of days prescription supply that enrollees could fill from 100 days to $\mathbf{3 4}$ days and increased copayments for brand-name medications. Previous work has shown that a change in these policies led to a decrease in medication adherence from 2.9 to 8.0 percentage points in specific populations with chronic conditions. Studies have also shown that days supply limits and copayment increases have heterogeneous effects based on enrollees' baseline characteristics, including baseline adherence. However, this phenomenon has not been studied in the Medicaid population. We undertook this study to assess the heterogeneous effect of the NC Medicaid policy changes in groups with varying levels of baseline adherence.
\end{abstract}

OBJECTIVE: To examine whether restrictions on days supply had heterogeneous effects in subgroups defined by medication adherence before the policy changes.

METHODS: A partial difference-in-difference-in-differences model with fixed effects was used to compare medication adherence before and after the NC Medicaid policy changes among Medicaid enrollees subject to the policy changes because of their use of long prescriptions ( $>40$ days) as compared with (a) NC Medicaid enrollees using short prescriptions ( $<40$ days) before policy adoption, as well as (b) Medicaid enrollees in Georgia restricted to a 31 days supply through the study period. Medicaid enrollees were included if they filled a prescription for 1 of the following medication classes: antihypertensives, lipid-lowering drugs, or antipsychotics. The effect of the policy changes on medication adherence, calculated using the proportion of days covered (PDC) each quarter by baseline adherence level and clinical condition group, was studied. Average adherence levels over the 18-month prechange period were used to stratify individuals into 3 baseline adherence groups: fully adherent $(\mathrm{PDC} \geq 80 \%)$, partially adherent $(50 \%-79 \%)$, and nonadherent (PDC $\leq 50 \%$ ).

RESULTS: Enrollees fully adherent at baseline observed a $2.0(P=0.001)$ and $1.2(P<0.001)$ percentage-point decline in adherence for the lipidlowering drug and antihypertensive cohorts, respectively, in the period after the policy changes. The nonadherent and partially adherent cohorts in the statin group observed an increase in adherence by 1.7-2.6 $(P<0.05)$ percentage points in the post-index period.

CONCLUSIONS: Adherence changes after cost containment policies have a heterogeneous effect on individuals with varying baseline adherence in the Medicaid population. Individuals fully adherent at baseline decreased adherence following policy changes, while individuals partially adherent and nonadherent at baseline either had no change or showed increases in adherence, possibly because of increased contact with pharmacists and clinicians required by shorter prescription lengths. Managed care strategies to control costs should take into consideration the heterogeneity of responses by the enrollees to these policies. Furthermore, policies that consider baseline characteristics of enrollees may be more effective in improving adherence.

J Manag Care Spec Pharm. 2017;23(3):337-45

Copyright $\odot 2017$, Academy of Managed Care Pharmacy. All rights reserved.

\section{What is already known about this subject}

North Carolina Medicaid program policies of decreased days supply and increased copayment for brand-name medications decreased medication adherence for Medicaid-enrolled populations with at least 1 of 6 chronic conditions by 2.9-8.0 percentage points on average.

Copayment changes affect medication adherence differentially by disease groups and patient populations: enrollees who are nonadherent at baseline have greater adherence improvements after copayment reductions than individuals who are fully adherent at baseline.

\section{What this study adds}

Medicaid enrollees who were fully adherent at baseline were more susceptible to decline in adherence after the change in policy. For the statin medication cohort, individuals who were nonadherent at baseline saw an increase in adherence, possibly because of increased pharmacist or clinician contact, leading to a better medication regimen.

A s pharmaceutical costs have increased 6 -fold over the past 2 decades, ${ }^{1}$ all states and the District of Columbia have implemented measures to meet budgetary pressures and contain Medicaid costs. ${ }^{2}$ Cost-containment strategies to reduce spending on pharmaceuticals have included steering enrollees toward lower-cost drugs by using tiered copayments strategies and reducing waste from enrollees switching prescribed medications through restrictions of the number of days supply filled. ${ }^{1-6}$

Previous studies show increased copayments and days supply limits, which cap the number of days of prescription drug supply per fill, have generally led to a decline in medication adherence with implications for downstream health care utilization costs. Higher copayments have been associated with lower medication adherence by $1.8-2.0$ percentage points in the commercial market ${ }^{7-10}$; by 4.4-6.2 percentage points among Medicare beneficiaries taking angiotensin-converting enzyme inhibitors, beta-blockers, or statins ${ }^{7} ; 2.0-7.0$ percentage points for veterans taking diabetes, hypertension, or hyperlipidemic medications ${ }^{11,12}$; and $0.16-4.6$ percentage points among Medicaid enrollees. ${ }^{13,14}$ 
More recently, researchers have demonstrated that prescription coverage policy changes can have a heterogeneous effect on medication adherence based on baseline characteristics of enrollees. The effect of the coverage policies may depend on enrollee characteristics present early after medications are prescribed,$^{15}$ including previous medication adherence rates and number of comorbidities. ${ }^{16,17}$ For example, a recent study of copayment reduction among persons with private insurance found that individuals who were previously nonadherent had greater adherence improvements than individuals who are fully adherent at baseline by 2.6-5.4 percentage points. ${ }^{16}$ The differential effect of prescription drug copayment policies, including reductions and increases, on subpopulations has important implications for prescription drug coverage designs and incentives intended to reduce overall health care costs for public and private payers. Although the value of stratified analyses in observing groups most affected by interventions has been discussed in the literature ${ }^{18}$ these studies are just the tip of the iceberg in understanding whether a fixed prescription coverage policy change affects individuals with varying baseline characteristics differently. To our knowledge, the impact of copayment increases and days supply limits on medication adherence for cohorts with varying prechange (baseline) adherence has not been studied, especially in the Medicaid population.

The North Carolina (NC) Medicaid program implemented a series of policies to reduce costs in 2001. On July 1, 2001, the maximum days supply for each prescription was decreased from 100 days to 34 days. This has the implicit effect of potentially tripling out-of-pocket costs for medications for those compliant with 100 days supply of medications, since 3 separate copayments were required for each 34-day fill. Additionally, copayments were increased for brand-name medications from $\$ 1$ to $\$ 3$ on October 1, 2001; there were no changes in copayments for generic medications during the study period. In a recent study, Domino et al. (2011) showed that both of these NC Medicaid program policy changes decreased medication adherence for specific populations, with at least 1 of the chronic conditions studied by 2.9-8.0 percentage points. ${ }^{13}$ However, Domino et al. did not examine whether there were heterogeneous differences in medication adherence changes by subgroups based on adherence level before the policy changes. The current study was undertaken to assess the differential effect of NC Medicaid policy changes on medication adherence for individuals with varying baseline adherence levels.

\section{Conceptual Model}

The restriction on maximum days supply for each prescription leads to an increase in time costs because of more frequent trips to dispensaries, as well as an increase in out-of-pocket costs, since copayments are made for every month's prescription refill instead of 1 refill every 3 months., ${ }^{6,13}$ More frequent contact with outpatient pharmacists, however, could increase adherence to medications through guidance on side-effects or dosing. ${ }^{19,20}$
Out-of-pocket and time costs affect enrollees in their use of prescriptions. While we studied the effect of copayment change for branded medications and restriction of days supply, based on previous studies of copayment reductions, ${ }^{16}$ we hypothesized that the policy changes would lead to differential effects by enrollees' baseline adherence behavior. Those fully adherent and partially adherent at baseline would see a greater increase in drug expenditures following the policy changes because of their higher prescription-filling behavior. As such, we hypothesized that the policy changes would lead to a greater reduction in adherence among individuals fully adherent at baseline than those partially adherent at baseline. However, enrollees who were fully adherent at baseline may have had unique characteristics, such as differences in caregiving support, greater perceived costs of nonadherence, intrinsic motivation, or disease severity, that led to better medication adherence before the policy changes and that may have made them less responsive to increases in out-of-pocket payments and restrictions on maximum days supply. ${ }^{15}$ It is, therefore, not obvious a priori whether these factors would outweigh the greater potential increase in costs from the policy change. We further hypothesized that individuals who were nonadherent at baseline would remain nonadherent after the NC Medicaid policy changes, even though they might benefit most from greater contact with pharmacists.

\section{Methods}

\section{Study Design and Data Sources}

Medicaid claims and enrollment data from the Centers for Medicare \& Medicaid Services for NC and a control state (Georgia [GA]) that did not implement a change in days supply were used with approval from the University of North Carolina Institutional Review Board. We analyzed measures aggregated to the quarterly level derived from claims data for the period of January 1, 2000-December 31, 2002. Quarterly analyses were used in order to smooth adherence over smaller time periods (such as monthly data) but to allow repeated observations on individuals in order to observe changes in behavior because of the policy change.

\section{Study Population}

Medicaid enrollees taking medications for at least 1 of 3 specific medication categories for chronic conditions-antihypertensives, lipid-lowering drugs, and antipsychotics-were studied separately. These 3 drug classes were studied because of their high prevalence in the Medicaid population. Because of potential off-label use, we excluded persons receiving antihypertensives who did not have a corresponding hypertension diagnosis (International Classification of Diseases, Ninth Revision, Clinical Modification [ICD-9-CM] codes 362.11, 401-405, and 997.91) and persons receiving antipsychotic medications without a corresponding diagnosis of psychotic disorders 


\begin{tabular}{c|c}
\hline FIGURE 1 & Partial DDD Method with \\
2 Comparison Groups
\end{tabular}

Treatment Group: NC Medicaid enrollees with long prescriptions (LP)

Comparison Group 1: NC Medicaid enrollees without LPs

Comparison Group 2: GA Medicaid enrollees without LPs

$\overline{D D D}=$ difference-in-difference-in-differences; $G A=$ Georgia; $L P=$ individuals receiving long prescriptions in the prechange period; $N C=$ North Carolina.

(ICD-9-CM codes 295, 296.2 V11.0, or 299) or bipolar disorders (ICD-9-CM code 296.8). We did not require the target diagnosis of hyperlipidemia for the lipid-lowering drug category because of limited off-label use. NC and GA Medicaid enrollees aged 18-64 years, who obtained a total of at least 90 days supply of medications during the 18-month prechange period (and thus were determined to be using medications for chronic conditions), were included in each of the 3 previously listed medication categories. Enrollees who were in a health maintenance organization or a nursing home, who were pregnant, or who had died were excluded for the relevant quarters. Data from the third quarter of 2002 for GA enrollees were removed because of extremely low prescriptions in 1 month of the raw claim files.

\section{Key Variables of Interest}

This study uses the proportion of days covered (PDC) measure of adherence. PDC is the fraction of days in a quarter for which at least 1 medication in the target class was filled. PDC is more conservative at the class level compared with other measures of calculating adherence and therefore preferred..$^{21}$ To accurately represent nonadherence, the PDC value of zero was assigned for months without a prescription after either diagnosis or first prescription fill for target medication. PDC was adjusted for inpatient stays because of lack of data on prescription adherence during hospitalizations for target conditions in each quarter. Adjusting for inpatient days did not significantly alter adherence level because of the small percentage of target inpatient days in a quarter (correlation of PDC unadjusted and adjusted for inpatient days was greater than 0.957 for all disease cohorts).

\section{Analytical Methods}

Following Domino et al., ${ }^{13}$ this study used a partial differencein-difference-in-differences (DDD) method with individuallevel fixed effects to evaluate the effect of the changed policies on heterogeneous Medicaid beneficiaries in NC. A partial DDD model examined time trends before and after the policy change in a treatment group, an in-state control group not affected by the policy change, and an out-of-state control state (Figure 1). The NC Medicaid beneficiaries were divided into 2 groups: (1) a treatment group of beneficiaries who were more likely to be affected by the change in policies, since they were prescribed long prescriptions (LPs) in the prechange period (a long prescription was defined as having at least 1 prescription for more than 40 days, following previous literature $\left.{ }^{13}\right)$ and (2) an in-state control group of beneficiaries who were not likely to be affected by the policy changes because they did not receive LPs. GA was selected as a control state because of similarity to NC in terms of size, poverty rate, and percentage of Hispanics and African Americans. ${ }^{13}$ We could not find another state that allowed LPs similar to NC's policy before the policy change during the full study period. GA was selected as a comparison state because, in addition to having similar characteristics to NC, it restricted days supply to 31 days throughout the entire study period. An out-of-state comparison group controlled for national or regional factors that might affect adherence and might change over the study period, such as changes in medications available for treatment or changes in the scientific literature. Therefore, differences were compared along 3 dimensions: pre/post policy change, NC/GA, and short/long prescriptions. We refer to this as a partial DDD model, since GA did not have an LP cohort. To our knowledge, there were no major changes in generic or brand-name medication copayment policies in GA during this study period..$^{13}$ The partial DDD model controls for changes in health trends among Medicaid enrollees across states, as well as for other NC-level policy changes that may have affected people receiving long and short prescriptions. ${ }^{22}$ We used individual-level fixed effects in the model to control for time-invariant factors, such as gender, region, race, ethnicity, and comorbidities in each population.

A transition period was assigned for the quarter (July 1, 2001-September 30, 2001) during which only the maximum days supply limit was in place, whereas the postperiod, defined as all quarters after September 2001, includes effects of both policy changes (Figure 1). The medication adherence (PDC) coefficients for the transition and postperiods were similar based on F-tests; therefore, only the postperiod results are reported here.

Following Hirsch et al. (2009), ${ }^{23}$ prechange average adherence levels were used to stratify individuals into 3 groups: fully adherent (PDC $\geq 80 \%$ ), partially adherent (50\%-79\%), and nonadherent (PDC $\leq 50 \%)$. A separate model was run for each of the 3 baseline adherence groups and the 3 disease categories, yielding 9 regressions.

The partial DDD with the fixed effects regression model used in this study is described by the following equation:

$$
\begin{gathered}
\mathrm{PDC}_{\mathrm{it}}=\beta_{\mathrm{Oi}}+\beta_{1} \text { Transition }_{\mathrm{it}}+\beta_{2} \text { Post }_{\mathrm{it}}+\beta_{3} \mathrm{NCi} \times \\
\text { Transition } \\
+\mathrm{it}+\beta_{4} \mathrm{NC}_{\mathrm{i}} \times \text { Post }_{\mathrm{it}}+\beta_{5} \text { Age }_{\mathrm{it}}+\beta_{6} \mathrm{NC}_{\mathrm{i}} \times \mathrm{LP}_{\mathrm{i}} \times \\
\text { Transition }_{\mathrm{it}}+\beta_{7} \mathrm{NC}_{\mathrm{i}} \times \mathrm{LP}_{\mathrm{i}} \times \text { Post }_{\mathrm{it}}+\varepsilon_{\mathrm{it}}
\end{gathered}
$$

Where Transition and Post indicate the first quarter and subsequent quarters after the days supply change, respectively, 


\begin{tabular}{|c|c|c|c|c|c|c|}
\hline \multirow[b]{3}{*}{ Patient Characteristics } & \multicolumn{3}{|c|}{ North Carolina } & \multicolumn{3}{|c|}{ Georgia } \\
\hline & \multicolumn{3}{|c|}{ Baseline Adherence } & \multicolumn{3}{|c|}{ Baseline Adherence } \\
\hline & $\begin{array}{l}\text { Fully Adherent } \\
\text { (PDC } \geq 80 \%)\end{array}$ & \begin{tabular}{|c|}
$\begin{array}{c}\text { Partially Adherent } \\
\text { (PDC 50\%-79\%) }\end{array}$ \\
\end{tabular} & $\begin{array}{c}\text { Non-adherent } \\
(\text { PDC } \leq 50 \%)\end{array}$ & $\begin{array}{l}\text { Fully Adherent } \\
\text { (PDC } \geq 80 \%)\end{array}$ & \begin{tabular}{|c|}
$\begin{array}{c}\text { Partially Adherent } \\
\text { (PDC 50\%-79\%) }\end{array}$ \\
\end{tabular} & $\begin{array}{c}\text { Nonadherent } \\
(\text { PDC } \leq 50 \%)\end{array}$ \\
\hline \multicolumn{7}{|l|}{ Lipid-lowering drugs cohort } \\
\hline Age, mean (SD) & $53.8 \quad(8.5)$ & $52.6 \quad(9.0)$ & $51.2 \quad(9.5)$ & $53.9 \quad(8.4)$ & $52.5 \quad(9.0)$ & $51.2 \quad(9.7)$ \\
\hline Male, $\%$ & 36.5 & 34.4 & 34.3 & 31.5 & 31.2 & 30.9 \\
\hline White, \% & 57.9 & 52.4 & 50.7 & 56.4 & 45.5 & 42.8 \\
\hline African American, $\%$ & 26.1 & 31.1 & 33.1 & 28.9 & 38.7 & 42.8 \\
\hline Other, \% & 16.0 & 16.5 & 16.3 & 14.7 & 15.9 & 14.4 \\
\hline Latino/a, \% & 0.2 & 0.5 & 0.7 & 0.3 & 0.4 & 0.5 \\
\hline $\begin{array}{l}\text { Number of diagnoses other than } \\
\text { hyperlipidemia, mean (SD) }\end{array}$ & $4.0 \quad(2.7)$ & $4.2 \quad(2.9)$ & $3.9 \quad(2.9)$ & $2.6 \quad(2.4)$ & $2.6 \quad(2.5)$ & $2.5 \quad(2.5)$ \\
\hline $\begin{array}{l}\text { Received LP in prechange } \\
\text { period, \% }\end{array}$ & 28.2 & 28.7 & 28.8 & - & - & - \\
\hline PDC, mean (SD) & $0.89 \quad(0.05)$ & $0.68 \quad(0.10)$ & $0.37 \quad(0.16)$ & $0.90 \quad(0.06)$ & $0.68 \quad(0.10)$ & $0.38 \quad(0.16)$ \\
\hline Unique individuals & 7,925 & 9,251 & 7,571 & 5,650 & 5,598 & 4,493 \\
\hline Total observations & 87,788 & 95,637 & 71,856 & 57,696 & 52,491 & 38,975 \\
\hline \multicolumn{7}{|c|}{ Antihypertensives cohort (diagnosis required) } \\
\hline Age, mean (SD) & $52.8 \quad(9.3)$ & $49.8 \quad(10.2)$ & $47.4 \quad(10.8)$ & $52.2 \quad(9.3)$ & $49.1 \quad(10.2)$ & $46.8 \quad(10.8)$ \\
\hline Male, $\%$ & 31.8 & 32.5 & 34.3 & 27.0 & 27.3 & 27.7 \\
\hline White, \% & 40.2 & 36.5 & 33.3 & 35.3 & 28.7 & 24.1 \\
\hline African American, \% & 44.6 & 48.3 & 52.7 & 50.1 & 59.1 & 65.7 \\
\hline Other, \% & 15.2 & 15.2 & 14.0 & 14.6 & 12.2 & 10.2 \\
\hline Latino/a, \% & 0.3 & 0.5 & 0.6 & 0.2 & 0.1 & 0.2 \\
\hline $\begin{array}{l}\text { Number of diagnoses other than } \\
\text { hypertension, mean (SD) }\end{array}$ & $4.4 \quad(2.8)$ & $4.3 \quad(2.9)$ & $3.9 \quad(2.8)$ & $3.4 \quad(2.6)$ & $3.2 \quad(2.6)$ & $2.9 \quad(2.5)$ \\
\hline $\begin{array}{l}\text { Received LP in prechange } \\
\text { period, } \%\end{array}$ & 40.7 & 36.2 & 31.0 & - & - & - \\
\hline PDC, mean (SD) & $0.91 \quad(0.05)$ & $0.69 \quad(0.11)$ & $0.38 \quad(0.18)$ & $0.91 \quad(0.06)$ & $0.69 \quad(0.11)$ & $0.38 \quad(0.27)$ \\
\hline Unique individuals & 26,147 & 19,706 & 15,550 & 14,301 & 11,254 & 9,999 \\
\hline Total observations & 287,419 & 193,762 & 137,746 & 145,165 & 101,544 & 82,088 \\
\hline \multicolumn{7}{|c|}{ Antipsychotic cohort (diagnosis required) } \\
\hline Age, mean (SD) & $44.5 \quad(11.1)$ & $42.3 \quad(11.3)$ & $39.7 \quad(11.0)$ & $42.7 \quad(11.1)$ & $41.1 \quad(11.1)$ & $39.7 \quad(10.7)$ \\
\hline Male, $\%$ & 51.6 & 46.5 & 44.6 & 45.0 & 39.4 & 42.4 \\
\hline White, $\%$ & 52.3 & 49.2 & 43.7 & 44.1 & 34.3 & 29.5 \\
\hline African American, \% & 36.4 & 38.7 & 44.2 & 45.1 & 54.4 & 59.6 \\
\hline Other, $\%$ & 11.3 & 12.2 & 12.2 & 10.9 & 11.4 & 10.9 \\
\hline Latino/a, \% & 0.3 & 0.6 & 0.5 & 0.4 & 0.3 & 0.3 \\
\hline $\begin{array}{l}\text { Number of diagnoses other than } \\
\text { psychotic or bipolar disorders, } \\
\text { mean (SD) }\end{array}$ & $4.1 \quad(2.7)$ & $4.7 \quad(3.2)$ & $4.9 \quad(3.2)$ & $2.9 \quad(2.2)$ & $3.5 \quad(2.7)$ & $\begin{array}{ll}3.6 & (2.7)\end{array}$ \\
\hline $\begin{array}{l}\text { Received LP in prechange } \\
\text { period (\%) }\end{array}$ & 25.1 & 21.5 & 14.4 & - & - & - \\
\hline PDC, mean (SD) & $0.90 \quad(0.05)$ & $0.69 \quad(0.10)$ & $0.35 \quad(0.15)$ & $0.90 \quad(0.05)$ & $0.67 \quad(0.10)$ & $0.35 \quad(0.15)$ \\
\hline Unique individuals & 6,529 & 4,003 & 3,323 & 4,361 & 3,269 & 3,058 \\
\hline Total observations & 74,522 & 42,605 & 33,133 & 45,859 & 32,517 & 28,535 \\
\hline
\end{tabular}

$\beta$ are coefficients on each of the model terms, $i$ indexes individuals, while $t$ indexes quarters. The main variable of interest was the interaction term between the NC indicator, the LP indicator, and the transition and postperiods. This variable can be interpreted as the additional effect of the policy changes on the treatment group (LPs in NC) compared with the prechange period adherence controlling for the changes in adherence across states over time and within NC. In addition to each of the time-varying indicators (transition period and postperiod) and pairwise interaction variables between groups (NC vs. 

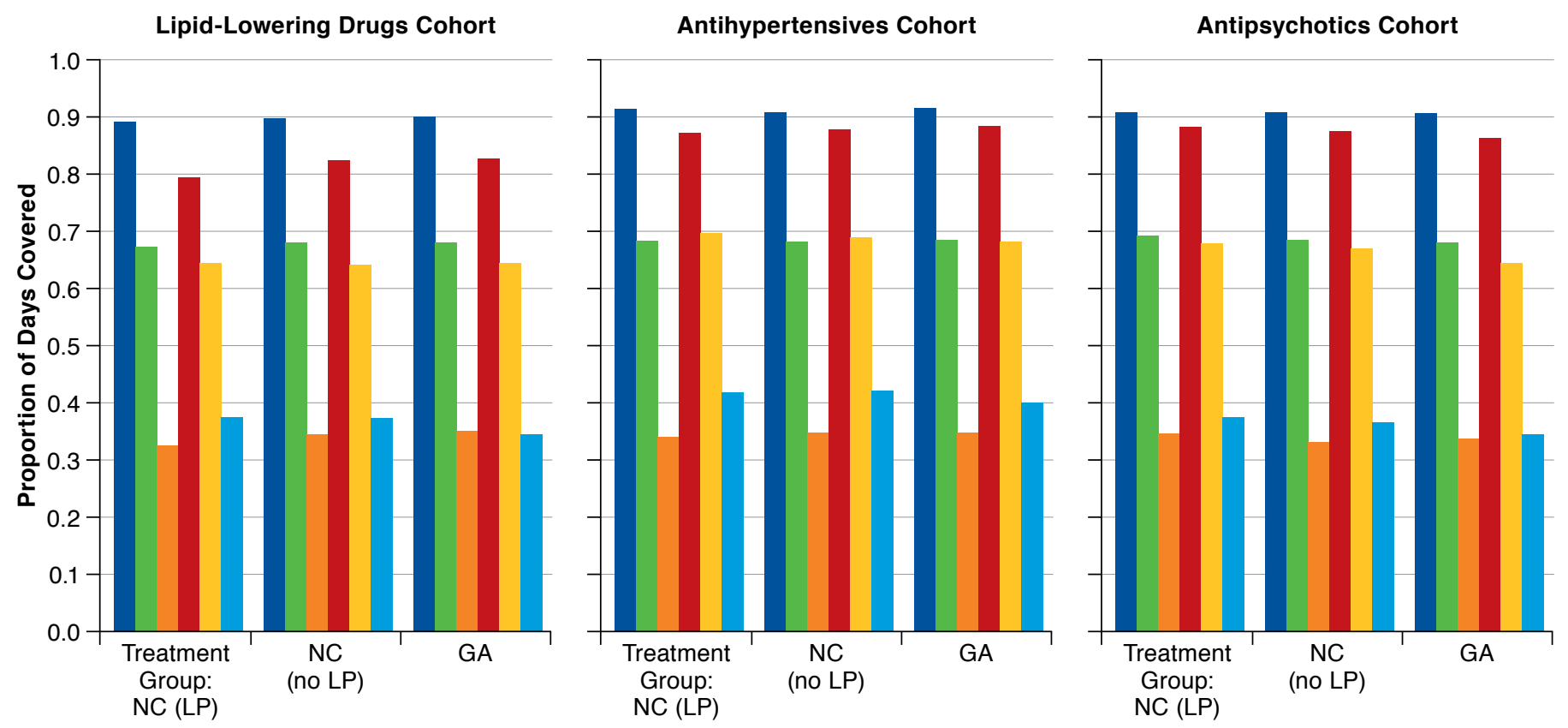

- Prechange fully adherent (PDC $\geq 80 \%)$ Prechange partially adherent (PDC 50\%-79\%)

Postchange fully adherent (PDC $\geq 80 \%)$ Postchange partially adherent (PDC 50\%-79\%)

Prechange nonadherent (PDC $\leq 50 \%)$

Postchange nonadherent (PDC $\leq 50 \%)$

$L P=$ individuals receiving long prescriptions in the prechange period; $N C=$ North Carolina; $G A=$ Georgia; $P D C=$ proportion of days covered.

GA and LPs vs. non-LPs), the analysis also controlled for age. Robust standard errors are reported.

\section{Results}

\section{Descriptive Statistics}

There were 40,520, 97,173, and 24,555 unique individuals and 252,869-921,069 total observations in the statin, hypertension, and antipsychotics disease cohorts, respectively (Table 1). Individuals in NC had similar characteristics to those in GA in terms of age, gender, race, and outcomes measures, as has been described in previous work. ${ }^{13}$

The proportion of individuals by gender and race/ethnicity were similar between the 3 baseline adherence groups; however, the fully adherent group tended to be older and more likely to be male (Table 1). The fully adherent enrollees at baseline in NC had a higher proportion of individuals receiving LPs in the prechange period for the hypertension and antipsychotics condition groups (41\% compared with $31 \%$ and 36\% for hypertension cohort; $25 \%$ compared with $14 \%$ and $22 \%$ for antipsychotics cohort; and 28\% compared with 29\% and 29\% for the statins disease cohort). This is expected, since the LP cohort by definition filled prescriptions for longer periods of time (> 40 days supply) in the prechange period and was therefore captured as having higher adherence by the PDC measure.

\section{Unadjusted Adherence Comparisons}

Before the NC Medicaid policy changes, average adherence (PDC) levels were similar across treatment and comparison groups for each of the 3 condition cohorts (Figure 2). Among enrollees fully and partially adherent at baseline, average adherence declined before and after the policy changes for all 3 medication cohorts (Figure 2). Enrollees who were nonadherent at baseline had an increase in adherence before and after the policy changes in NC for all 3 of the condition cohorts.

\section{DDD Stratified Analyses}

In adjusted analyses, a decrease in medication adherence was observed for the fully adherent at baseline for the statin and hypertension disease cohorts after the policy changes. The fully adherent enrollees decreased adherence by $2.0 \%$ $(P=0.001 ; 95 \%$ confidence interval $[C \mathrm{CI}]:-0.032,-0.009)$ and $1.2 \%(P<0.001 ; 95 \% \mathrm{CI}:-0.017,-0.008)$ for the statin and hypertension cohorts, respectively (Table 2 and Figure 3).

The nonadherent and partially adherent treatment groups increased adherence after the policy changes by $2.6 \%(P=0.004$; 
TABLE 2 DDD Results for the Effect of Policy Changes on Adherence for Individuals in NC with LPS, Compared with Others in NC and GA in Postchange Period

\begin{tabular}{|c|c|c|c|}
\hline & \multicolumn{3}{|c|}{ Prechange Adherence } \\
\hline & $\begin{array}{l}\text { Fully Adherent } \\
(\text { PDC } \geq 80 \%)\end{array}$ & $\begin{array}{c}\text { Partially Adherent } \\
\text { (PDC 50\%-79\%) }\end{array}$ & $\begin{array}{l}\text { Nonadherent } \\
\text { (PDC } \leq 50 \%)\end{array}$ \\
\hline \multicolumn{4}{|l|}{ Lipid-lowering drugs } \\
\hline Age & $0.0208^{\mathrm{a}}(0.0010)$ & $0.0327^{\mathrm{a}}(0.0020)$ & $-0.01999^{a}(0.0026)$ \\
\hline \multicolumn{4}{|l|}{ Variables for postchange period } \\
\hline $\mathrm{NC}_{\mathrm{i}} \times \mathrm{LP}_{\mathrm{i}} \times$ Post $_{\mathrm{it}}$ (postperiod difference for LPs above other controls) & $-0.0202^{\mathrm{a}}(0.0058)$ & $0.0166^{b} \quad(0.0073)$ & $0.0263^{\mathrm{a}}(0.0091)$ \\
\hline $\mathrm{NC}_{\mathrm{i}} \times$ Post $_{\mathrm{it}}$ (postperiod differences between all NC enrollees compared with GA) & $0.0024 \quad(0.0042)$ & $0.0048 \quad(0.0058)$ & $0.0302^{\mathrm{a}}(0.0071)$ \\
\hline Postperiod intercept (average differences between post- and prechange periods for NC and GA) & $-0.0990^{\mathrm{a}}(0.0031)$ & $-0.0917^{\mathrm{a}}(0.0046)$ & $0.0197^{\mathrm{a}}(0.0056)$ \\
\hline Unique individuals & 13,572 & 14,858 & 12,090 \\
\hline Total observations & 140,205 & 136,113 & 102,366 \\
\hline \multicolumn{4}{|l|}{ Antihypertensives (diagnosis required) } \\
\hline Age & $0.0219^{a}(0.0005)$ & $0.0453^{\mathrm{a}}(0.0013)$ & $0.0194^{a}(0.0021)$ \\
\hline \multicolumn{4}{|l|}{ Variables for postchange period } \\
\hline $\mathrm{NC}_{\mathrm{i}} \times \mathrm{LP}_{\mathrm{i}} \times$ Post $_{\mathrm{it}}$ (postperiod difference for LPs above other controls) & $-0.0123^{a}(0.0022)$ & $0.0047 \quad(0.0043)$ & $0.0067 \quad(0.0062)$ \\
\hline $\mathrm{NC}_{\mathrm{i}} \times$ Post $_{\mathrm{it}}$ (postperiod differences between all NC enrollees compared with GA) & $0.0028 \quad(0.0019)$ & $0.0088^{b}(0.0036)$ & $0.0072 \quad(0.0058)$ \\
\hline Postperiod intercept (average differences between post- and prechange periods for NC and GA) & $-0.0570^{\mathrm{a}}(0.0014)$ & $-0.0547^{\mathrm{a}}(0.0028)$ & $0.0593^{a}(0.0040)$ \\
\hline Unique individuals & 40,454 & 31,016 & 25,703 \\
\hline Total observations & 428,192 & 283,889 & 208,988 \\
\hline \multicolumn{4}{|l|}{ Antipsychotics (diagnosis required) } \\
\hline Age & $0.0186^{\mathrm{a}}(0.0009)$ & $0.0329^{a}(0.0025)$ & $0.0177^{\mathrm{a}}(0.0034)$ \\
\hline \multicolumn{4}{|l|}{ Variables for postchange period } \\
\hline $\mathrm{NC}_{\mathrm{i}} \times \mathrm{LP}_{\mathrm{i}} \times$ Post $_{\mathrm{it}}$ (postperiod difference for LPs above other controls) & $0.0000 \quad(0.0043)$ & $-0.0068 \quad(0.0114)$ & $0.0260 \quad(0.0181)$ \\
\hline $\mathrm{NC}_{\mathrm{i}} \times$ Post $_{\mathrm{it}}$ (pos period differences between all NC enrollees compared with GA) & $0.0190^{\mathrm{a}}(0.0034)$ & $0.0085 \quad(0.0070)$ & $0.0309 \quad(0.0090)$ \\
\hline Postperiod intercept (average differences between post- and prechange periods for NC and GA) & $-0.0637^{\mathrm{a}}(0.0027)$ & $-0.0438^{a}(0.0053)$ & $0.0177^{\mathrm{a}}(0.0066)$ \\
\hline Unique individuals & 10,890 & 7,276 & 6,389 \\
\hline Total observations & 119,883 & 73,337 & 59,649 \\
\hline
\end{tabular}

Note: Data in table are presented as interaction term coefficients (robust standard error). Interaction terms are those between the baseline adherence groups and the treatment (Post/NC/LP) indicators.

${ }^{a} P<0.01$

${ }^{b} \mathrm{P}<0.05$.

$D D D=$ difference-in-difference-in-differences; $G A=$ Georgia; $L P=$ individuals receiving long prescriptions in prechange period; $N C=$ North Carolina;

$P D C=$ proportion of days covered.

95\% CI: $0.008,0.044)$ and $1.7 \%(P<0.05 ; 95 \% C I: 0.002$, $0.031)$ in the statin condition group and by $0.7 \%(P=0.28)$ and $0.5 \%(P=0.27)$ in the hypertension condition group, respectively. For the antipsychotics cohort, medication adherence did not change significantly after the NC policy changes across any of the baseline adherence groups.

A sensitivity analysis of the study cohort without beneficiaries who had dual eligibibility for Medicaid and Medicare (not reported in tables) showed the same trends as the analysis of the study cohort that included those with dual eligibility reported here. Removing the enrollees with dual eligibility from the analysis reduced the significance of the results.

\section{Discussion}

The cohorts that were fully adherent (PDC $\geq 80 \%)$ at baseline to statins or antihypertensives were the most affected by the policy changes, with a marked decrease in adherence as a result of the policy changes (Table 2 and Figure 3). On the other hand, those who were nonadherent to medication before the policy changes (PDC $\leq 50 \%$ ) showed either no effect from the policy changes (antihypertensives or antipsychotics) or showed greater adherence (statins).

Individuals in the statin cohort who were nonadherent at baseline had a $2.6 \%$ increase in adherence in the postchange period, and partially adherent patients had a $1.7 \%$ adherence increase. Although not examined directly in this study, decreasing days supply limits from 100 to 34 days may inadvertently increase clinical contact with a pharmacist through the need to fill medications more frequently. Although speculative, this additional contact could have led to better medication adherence. It is unclear why this effect is isolated to the statin cohort. Previous studies have shown that individuals on statins are especially likely to improve medication adherence through physician follow-up. ${ }^{24}$

In contrast, the fully adherent statin cohort had a 2.0 percentage-point decrease in adherence relative to trends in 
FIGURE 3 Medication Adherence Change for Individuals in NC with LPs, Compared with Controls, by Baseline Adherence Stratifications in the Postchange Period

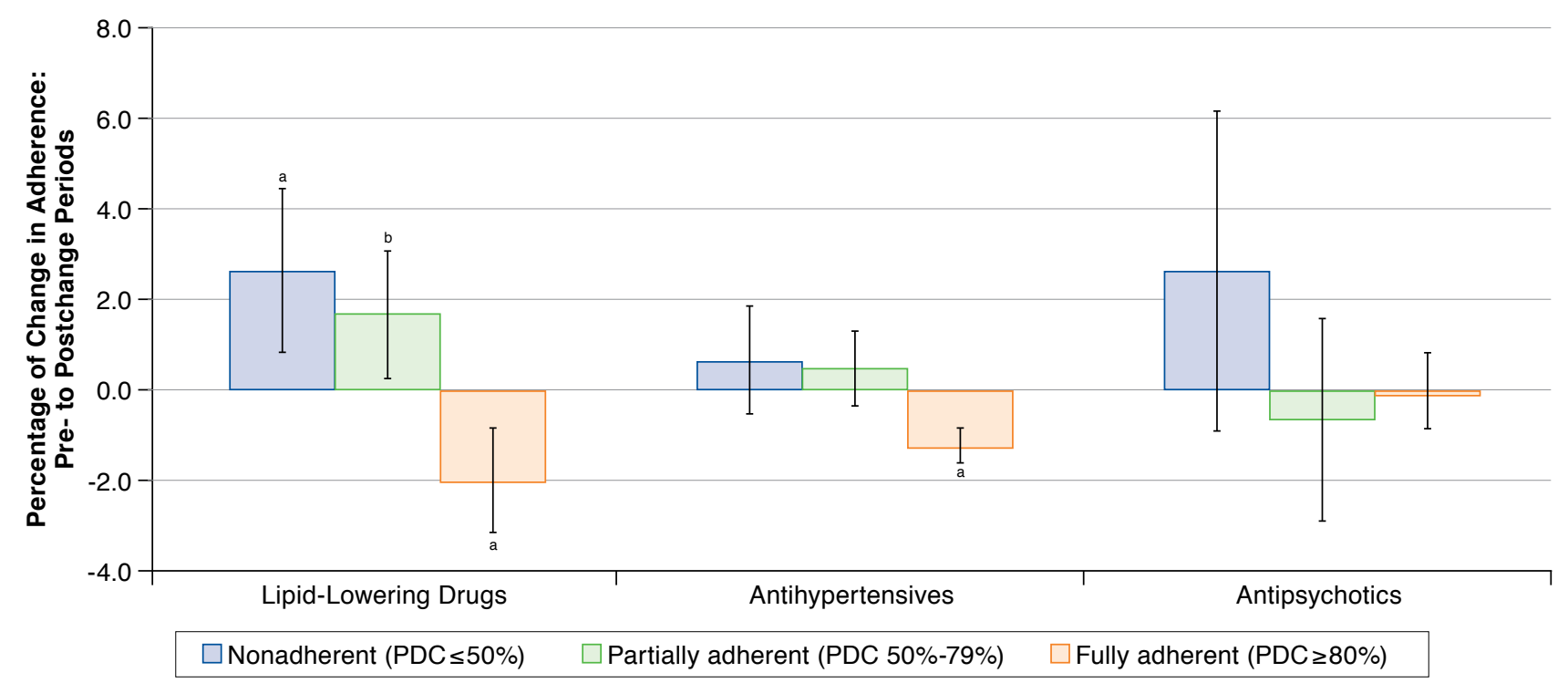

Note: This figure shows main interaction term $\left(N C_{i} \times L P_{i} \times\right.$ Post $\left._{i j}\right)$ coefficients with robust confidence intervals error bars.

a Reject the null hypothesis that the main interaction term coefficient is equal to $0, P$ value $<0.01$.

${ }^{b}$ Reject the null hypothesis that the main interaction term coefficient is equal to $0, P$ value $<0.05$.

$L P=$ individuals receiving long prescriptions in prechange period; NC $=$ North Carolina; $P D C=$ proportion of days covered.

the control groups. The NC policy changes increased monetary costs for enrollees through an increase in brand-name drug copayments. Furthermore, the change in the days supply limit from 100 days to 34 days tripled the number of pharmacy visits required for refills-increasing time costs as well as tripling out-of-pocket costs for those who were fully adherent. We speculated that enrollees who were fully adherent at baseline may have greater changes in costs because of the policy changes but may also have unique characteristics, such as differences in caregiving support, greater perceived costs of nonadherence, intrinsic motivation, or disease severity, that might lead to better medication adherence before the policy changes and might make them less responsive to copayment increases and restrictions on maximum days supply.

Our results demonstrated that the enrollees who were fully adherent at baseline were particularly affected by the policies, which reduced adherence..$^{15}$ Furthermore, the dual policy changes increased copayments for brand-name drugs from $\$ 1$ for 100 days supply to $\$ 3$ for 34 days supply or $\$ 9$ for almost 100 days supply, which is up to a 9-fold increase in out-ofpocket spending. Fully adherent patients in the hypertension cohort had a 1.2 percentage-point decrease in adherence, while adherence was unchanged in the postchange period in the nonadherent and partially adherent cohorts. Our data show that Medicaid enrollees who were fully adherent at baseline were more susceptible to decline in adherence, perhaps because of increased time and monetary costs. However, the magnitude of the change in adherence for this group, at a 0.5-2.0 percentagepoint decrease, is clinically modest; clinical literature lacks data on the clinical implications of such an adherence change. Given that health outcomes and health care resource use implications of nonadherence were more immediate among the antipsychotics user group than the statin or antihypertensive cohorts, it is not surprising that our results were not significant for this cohort across baseline adherence groups.

This study adds to the growing literature on the importance of stratified analyses to understand the heterogeneous effect of policy changes on cohorts with varying baseline characteristics. The days supply limit and the increase in copayments affect individuals with varying baseline adherence differentials. Policies that include patient follow-up to maintain medication adherence may be effective in improving or sustaining medication adherence for chronic conditions. Such interventions include those that monitor and provide feedback to patients or deliver educational counseling through clinicians or pharmacists over multiple sessions..$^{25-27}$ To further inform insurance coverage decisions, future studies should examine the effect of prescription drug coverage policies on subsequent health service use because of decreased medication adherence by stratified baseline adherence groups. 


\section{Limitations}

Several limitations should be noted in interpreting this study's results. PDC was based on Medicaid-paid prescription fills and may not reflect actual medication adherence. ${ }^{28-30}$ In addition, this study only includes individuals who had previously received at least a 90-day supply of medications for the 3 target chronic conditions and may not be applicable for individuals initiating treatment for other chronic conditions, as is evident by the differences in findings across the disease groups studied. The DDD models do not control for time-varying factors other than age, which could potentially lead to omitted variable bias. For example, unobserved disease severity may change over time for individuals unrelated to either age or individual characteristics and may affect adherence levels. However, we do not anticipate that this bias differentially affects our intervention versus control groups. Any other characteristics that would disproportionately affect those in the LP group in NC during the postchange period are at risk of being attributed to the policy changes.

\section{Conclusions}

Adherence changes after cost-containment policies have heterogeneous effects on individuals with varying baseline adherence in the Medicaid population. We observed different effects for those who were fully adherent compared with those who were nonadherent at baseline in extent of adherence change, as well as directionality. Future research should examine the reasons for differential effects of policy changes on cohorts with different levels of baseline adherence. Managed care organizations structuring insurance designs to improve medication adherence behavior ought to consider the heterogeneous effect of such policies on cohorts with varying baseline adherence. Policies that consider the baseline characteristics of enrollees may be more effective in improving adherence.

\section{Authors}

KRUTIKA AMIN, MSPH, Centers for Medicare \& Medicaid Services, Washington, DC; JOEL F. FARLEY, PhD, University of North Carolina Eshelman School of Pharmacy, Chapel Hill; MATTHEW L. MACIEJEWSKI, PhD, Center for Health Services Research in Primary Care, Durham VA Medical Center, and Division of General Internal Medicine, Department of Medicine, Duke University Medical Center, Durham, North Carolina; and MARISA E. DOMINO, PhD, Department of Health Policy and Management, The Gillings School of Global Public Health, University of North Carolina, Chapel Hill.

AUTHOR CORRESPONDENCE: Marisa E. Domino, PhD, Department of Health Policy and Management, The Gillings School of Global Public Health, University of North Carolina, 1104G McGavran-Greenberg Hall, CB\#7411, 135 Dauer Dr., Chapel Hill, NC 27599-7411. Tel.: 919.966.3891; E-mail: domino@unc.edu.

\section{DISCLOSURES}

This study was partly funded by a grant from the Robert Wood Johnson Foundation for use in data creation. Maciejewski was supported by a Research Career Scientist Award from the Department of Veterans Affairs (RCS 10-391) and owns stock in Amgen. Farley reports consultancy fees from Daiichi Sankyo outside of the conduct of this study. The other authors report no financial or other conflicts of interest related to the subject of this article. The views expressed in this article are those of the authors and do not reflect the position or policy of the Centers for Medicare \& Medicaid Services, University of North Carolina at Chapel Hill, Department of Veteran Affairs, or Duke University.

Study design and concept were contributed by Amin and Domino, along with Farley and Maciejewski. Domino collected the data, and data interpretation was performed primarily by Amin, along with Domino, with assistance from Farley and Maciejewski. The manuscript was primarily written by Amin, along with Domino, and revised by all the authors.

\section{ACKNOWLEDGMENTS}

Support from the Changes in Health Care Financing \& Organization Initiative at the Robert Wood Johnson Foundation and AcademyHealth for the creation of the study data is gratefully acknowledged.

\section{REFERENCES}

1. Kaiser Family Foundation. Prescription drug trends fact sheet-May 2010 update. May 2, 2010. Available at: http://kff.org/health-costs/fact-sheet/prescription-drug-trends-fact-sheet-may-2010/. Accessed December 20, 2016.

2. Smith V, Ramesh R, Gifford K, Ellis E, Rudowitz R, O'Malley M. The continuing Medicaid budget challenge: state Medicaid spending growth and cost containment in fiscal years 2004 and 2005. Results from a 50-state survey. Kaiser Commission on Medicaid and the Uninsured. October 2004 Available at: https://kaiserfamilyfoundation.files.wordpress.com/2013/01/ the-continuing-medicaid-budget-challenge-state-medicaid-spending-growthand-cost-containment-in-fiscal-years-2004-and-2005-results-from-a-50-state-survey.pdf. Accessed December 20, 2016.

3. Hoadley J. Cost containment strategies for prescription drugs: assessing the evidence in the literature. Kaiser Family Foundation. March 2005. Available at: https://kaiserfamilyfoundation.files.wordpress.com/2013/01/ cost-containment-strategies-for-precription-drugs-assessing-the-evidence-inthe-literature-report.pdf. Accessed December 20, 2016

4. Smith VK, Gifford K, Ellis E, Rudowitz R, Watts MO, Marks C. The crunch continues: Medicaid spending, coverage and policy in the midst of a recession. Results from a 50-state Medicaid budget survey for state fiscal years 2009 and 2010. Kaiser Family Foundation. September 2009. Available at: http://kff.org/medicaid/event/the-crunch-continues-medicaid-spendingcoverage-and/. Accessed December 20, 2016.

5. Hoadley JF, Cunningham P, McHugh M. Popular Medicaid programs do battle with state budget pressures: perspectives from twelve states. Health Aff (Millwood). 2004;23(2):143-54.

6. Domino ME, Olinick J, Sleath B, Leinwand S, Byrns PJ, Carey T. Restricting patients' medication supply to one month: saving or wasting money? Am J Health Syst Pharm. 2004;61(13):1375-79.

7. Cole JA, Norman H, Weatherby LB, Walker AM. Drug copayment and adherence in chronic heart failure: effect on cost and outcomes. Pharmacotherapy. 2006;26(8):1157-64.

8. Chernew ME, Shah MR, Wegh A, et al. Impact of decreasing copayments on medication adherence within a disease management environment. Health Aff (Millwood). 2008;27(1):103-12.

9. Colombi AM, Yu-Isenberg K, Priest J. The effects of health plan copayments on adherence to oral diabetes medication and health resource utilization. J Occup Environ Med. 2008;50(5):535-41. 
10. Gibson T, Mark T, Axelsen K, Baser O. Impact of statin copayments on adherence and medical care utilization and expenditures. Am J Manag Care. 2006;12(Spec no.):SP11-19. Available at: http://www.ajmc.com/journals/issue/2006/2006-12-vol12-n12SP/Dec06-2415pSP11-SP19/. Accessed December 20, 2016.

11. Doshi JA, Zhu J, Lee BY, Kimmel SE, Volpp KG. Impact of a prescription copayment increase on lipid-lowering medication adherence in veterans. Circulation. 2009;119(3):390-97.

12. Maciejewski ML, Bryson CL, Perkins M, et al. Increasing copayments and adherence to diabetes, hypertension, and hyperlipidemic medications Am J Manag Care. 2010;16(1):e20-34.

13. Domino ME, Martin BC, Wiley-Exley E, et al. Increasing time costs and copayments for prescription drugs: an analysis of policy changes in a complex environment. Health Serv Res. 2011;46(3):900-19.

14. Lieberman DA, Polinski JM, Choudhry NK, Avorn J, Fischer MA. Unintended consequences of a Medicaid prescription copayment policy. Med Care. 2014;52(5):422-27.

15. Adams AS, Uratsu C, Dyer W, et al. Health system factors and antihypertensive adherence in a racially and ethnically diverse cohort of new users. JAMA Intern Med. 2013;173(1):54-61.

16. Farley JF, Wansink D, Lindquist JH, Parker JC, Maciejewski ML. Medication adherence changes following value-based insurance design. Am J Manag Care. 2012;18(5):265-74.

17. Wang V, Liu C-F, Bryson CL, Sharp ND, Maciejewski ML. Does medication adherence following a copayment increase differ by disease burden? Health Serv Res. 2011;46(6 Pt 1):1963-85.

18. Hayward RA, Kent DM, Vijan S, Hofer TP. Reporting clinical trial results to inform providers, payers, and consumers. Health Aff (Millwood). 2005;24(6):1571-81.

19. van Boven JFM, Stuurman-Bieze AGG, Hiddink EG, Postma MJ, Vegter S. Medication monitoring and optimization: a targeted pharmacist program for effective and cost-effective improvement of chronic therapy adherence. J Manag Care Spec Pharm. 2014;20(8):786-92. Available at: http://www.jmcp. org/doi/10.18553/jmcp.2014.20.8.786.

20. Spence MM, Makarem AF, Reyes SL, et al. Evaluation of an outpatient pharmacy clinical services program on adherence and clinical outcomes among patients with diabetes and/or coronary artery disease. J Manag Care Spec Pharm. 2014;20(10):1036-45. Available at: http://www.jmcp.org/ doi/10.18553/jmcp.2014.20.10.1036.
21. Martin BC, Wiley-Exley EK, Richards S, Domino ME, Carey TS, Sleath BL. Contrasting measures of adherence with simple drug use, medication switching, and therapeutic duplication. Ann Pharmacother. 2009;43(1):36-44

22. Imbens GW, Wooldridge JM. Difference-in-differences estimation. Paper presented at: National Bureau of Economic Research Summer Institute 2007. July 31, 2007. Available at: http://www.nber.org/WNE/lect_10_diffindiffs.pdf. Accessed December 20, 2016.

23. Hirsch JD, Rosenquist A, Best BM, Miller TA, Gilmer TP. Evaluation of the first year of a pilot program in community pharmacy: HIV/AIDS medication therapy management for Medi-Cal beneficiaries. J Manag Care Pharm. 2009;15(1):32-4l. Available at: http://www.jmcp.org/doi/10.18553/ jmcp.2009.15.1.32.

24. Brookhart MA, Patrick AR, Schneeweiss S, et al. Physician follow-up and provider continuity are associated with long-term medication adherence: a study of the dynamics of statin use. Arch Intern Med. 2007;167(8):847-52.

25. Kripalani S, Yao X, Haynes RB. Interventions to enhance medication adherence in chronic medical conditions: a systematic review. Arch Intern Med. 2007;167(6):540-50.

26. Lee JK, Grace KA, Taylor AJ. Effect of a pharmacy care program on medication adherence and persistence, blood pressure, and low-density lipoprotein cholesterol: a randomized controlled trial. JAMA. 2006;296(21):2563-71.

27. Haynes RB, Yao X, Degani A, Kripalani S, Garg A, McDonald HP. Interventions to enhance medication adherence. Cochrane Database Syst Rev. 2005;(4):CD000011.

28. Choudhry NK, Shrank WH, Levin RL, et al. Measuring concurrent adherence to multiple related medications. Am J Manag Care. 2009;15(7): 457-64. Available at: https://www.ncbi.nlm.nih.gov/pmc/articles/ PMC2873865/?tool=pmcentrez. Accessed December 20, 2016.

29. McHorney CA, Victor Spain C, Alexander CM, Simmons J. Validity of the adherence estimator in the prediction of 9-month persistence with medications prescribed for chronic diseases: a prospective analysis of data from pharmacy claims. Clin Ther. 2009;31(11):2584-607.

30. Karve S, Cleves MA, Helm M, Hudson TJ, West DS, Martin BC. Prospective validation of eight different adherence measures for use with administrative claims data among patients with schizophrenia. Value Health. 2009;12(6):989-95. 